\title{
THE PRIORITIZATION OF CRITERIA FOR THE SELECTION OF RADAR FOR THE AIR TRAFFIC CONTROL AND PROTECTION BY MULTI-CRITERIA DECISION - MAKING APPLICATION IN THE FUZZY ENVIRONMENT*
}

\author{
Ivan B. Petrović \\ University of Defence in Belgrade, Military Academy, Republic of Serbia \\ Saša Sretović \\ Serbian Armed Forces, Air Force and Air Defence \\ Milan S. Kankaraš \\ University of Defence in Belgrade, Military Academy, Republic of Serbia
}

\begin{abstract}
The prioritization of criteria for the selection of radar for the air traffic control and protection by multi-criteria decision - making is presented in the paper. By analyzing the content of the available literature, the criteria and attributes of the criteria, on whose basis it is possible to evaluate the radar for the air traffic control, have been separated. The mutual influence of the criteria and attributes has been exerted by testing a group of experts using a questionnaire (the AHP questionnaire). The obtained values are fuzzificated in triangular fuzzy numbers. The processing of the gathered data - triangular fuzzy numbers and the prioritization of the criteria and attributes has been carried out by the AHP method. The consistency of the results has been tested by the ratio of consistency. On the basis of the results, the model that enables the selection of optimal radar for the air traffic control and protection has been proposed.
\end{abstract}

Key Words: Fuzzy-AHP, Air Traffic Control, Multi-Criteria Decision Making, Radar

\section{Introduction}

The expansion of the air traffic during the twentieth century resulted in a significant increase in the number of airspace users, different categories and types, which has led to the increase in the probability of emergencies in the airspace and threats to security.

\footnotetext{
* This paper is the result of the project VA-DH/3/17-19 "Calculation of Long-Term Financial Sustainability of the Duty Forces of Air Defense System of Serbian Armed Forces in Performing the Airspace Control and Protection in Peace". The project is funded by the Ministry of Defence, and the Project Manager is Assistant Professor Ivan Petrović.
} 
The Prioritization of Criteria for the Selection of Radar for the Air Traffic Control and Protection ...

The airspace control and protection is the right and obligation of every country. The airspace control involves the continuous detection of all objects in the airspace, as well as their monitoring and observation of all airspace activities. The air traffic control and protection is also a very profitable activity, whose improvement has been continuously done, as written by numerous authors (Petrović et al., 2014; Menon et al., 2004; Chen et al., 2017, etc).

It is necessary to understand that the support of air traffic management and the efficiency and effectiveness of the airspace control and protection depends to a large extent on the radar capability. The importance of radar and other air defence components in preventing the airspace violation and neutralizing the security threat from the air in peace has increased particularly since 9/11 (Petrović et al., 2015).

The Republic of Serbia is a small country in both qualitative and quantitative terms (about 8 million inhabitants, small area $-88,361 \mathrm{~km}^{2}$, small gross domestic product, relatively poor economic development, complex geostrategic and geopolitical position), which significantly impacts its equipment with the modern devices including radar. A special influence has been exerted from the territory of the country, as well as the current availability of air force and air defence on the selection of military radars (Gordić \& Petrović, 2014).

Bearing in mind the aforementioned, the research has been conducted with the general objective: the prioritization of the criteria for the selection of radar for the airspace control and protection in accordance with the capabilities of the country by the fuzzy-AHP method.

The abovestated research objective gives rise to the following general hypothesis:

On the basis of the fuzzy-AHP method, it is possible to evaluate the criteria for the selection of radar for the airspace control and protection in accordance with the capabilities of the country.

The application of the fuzzy-AHP method enables multi-criteria decision - making process by taking into consideration the uncertainties of the expert opinion, which has the impact on the scientific and methodological justification of the research. This procedure can, in its essence, be applied for the choice of a wide range of technological solutions in other spheres of social life, which makes this research practically justified.

\section{Review of Literature}

There is a lot of literature that deals with the evaluation of the criteria for the selection of weapons and military equipment. Mavris \& DeLaurentis (1995) investigated the concept of the "overall evaluation criteria" ("OEC") for determination of criteria for selecting the combat aircraft. The prioritization of the criteria for the combat aircraft by the AHP method was researched by Vlačić (2013). The application of the modified AHP method using the fuzzy numbers in the research of the defence system problems was researched by Božanić et al. (2015).

The possibilities and goals of improving the air defence system including anti-aircraft units were reseached by Petrović et al. (2015). The determination and evaluation of the criteria for the selection of anti-aircraft missile systems by the DEMATEL method were researched by Petrović \& Kankaraš (2017). The significant contribution to the application of conventional methods in the fuzzy environment for selection of the weapon was given by Dagdeviren et al. (2009).

However, the prioritization of the criteria for the selection of radar in the fuzzy environment has not been fully researched by any scientific paper. 


\section{Criteria for Selection of Radar}

On the basis of previously analyzed contents of literature, the criteria and attributes within each criterion have been determined, on whose basis it is possible to carry out the optimal selection of radar for the airspace control and protection (Sretović, 2018). The criteria are adapted to the overall evaluation criteria for the selection of the combat system (Mavris \& DeLaurentis, 1995). The radar selection criteria are as follows: affordability (A), spatial performance $(B)$, time performance (C), safety (D), and radar support capability of air defence weapons $(E)$.

The attributes of the affordability are: disposal costs (A1), training costs (A2), operating costs (A3), acquisition costs (A4) and logistics support (A5).

The attributes of the spatial performance are: the primary radar air surveillance zone (B1), the secondary radar air surveillance zone (B2), the fighter aircraft navigation zone (B3) and the number of necessary radars for organization of air surveillance fields (B4).

The attributes of the time performance are: the required time for the detection of an object in the airspace $(C 1)$, the required time for the $3 D$ position determination $(C 2)$, the required time for identification of airplane (C3), the required time for the course, speed, size of group and membership determination (C4) and the required time for dataprocessing of reconnaissance information (C5).

The attributes of the safety are: force protection (D1), maneuver ability (D2), remote control ability (D3), sensitivity to electronic attack (D4) and frequency agility (D5).

The attributes of the possibility of radar support for air defense weapons systems are: overall ability of navigation (E1), capability of simultaneous instrumental navigation (E2), ability of ground-air communication equipment (E3) and the ability of providing radar surveillance information to anti-aircraft missile systems (E4).

\section{Methodology}

For the purpose of prioritization of the criteria and attributes by the AHP (the analytic hierarchy process) method, the data has been gathered by the questionnaire, which has been adapted to the scale of relative importance [1/9, 9] (Saaty, 1980). The prioritization of the weights of elements based on their values has been carried out by the eigenvector (EV) method (Saaty, 1980). Four experts have performed pairwise comparison of criteria and attributes within each criterion. Bearing in mind the small number of experts and dispersion of the obtained values, the fuzzification of the crisp values has been done using the triangular fuzzy numbers (one of the group decision approaches has been applied).

The procedure of fuzzification has been carried out as follows:

Fuzzy set A for every real number $a$, has value $\mu(a)$, where $\mu(a)$ is degree of membership $a$ to triangular fuzzy numbers $A^{\prime}$ and can be in discrete interval $[0,1]$. Fuzzy set can be presented as follows $A=\{a, \mu(a)\}$. 
To each crisp value $a_{i j}$ two values are assigned and the triangular fuzzy number is formed, which is presented as a vector:

$$
a_{i j}^{\prime}=\left\{a_{i j}-\alpha, a_{i j}, a_{i j}+\alpha\right\} \text {, where is } 1 / 2 \leq \alpha \leq 1 \text {, in this case it is equal to } 1 .
$$

The aforementioned triangular fuzzy numbers characteristics are shown in Figure 1.

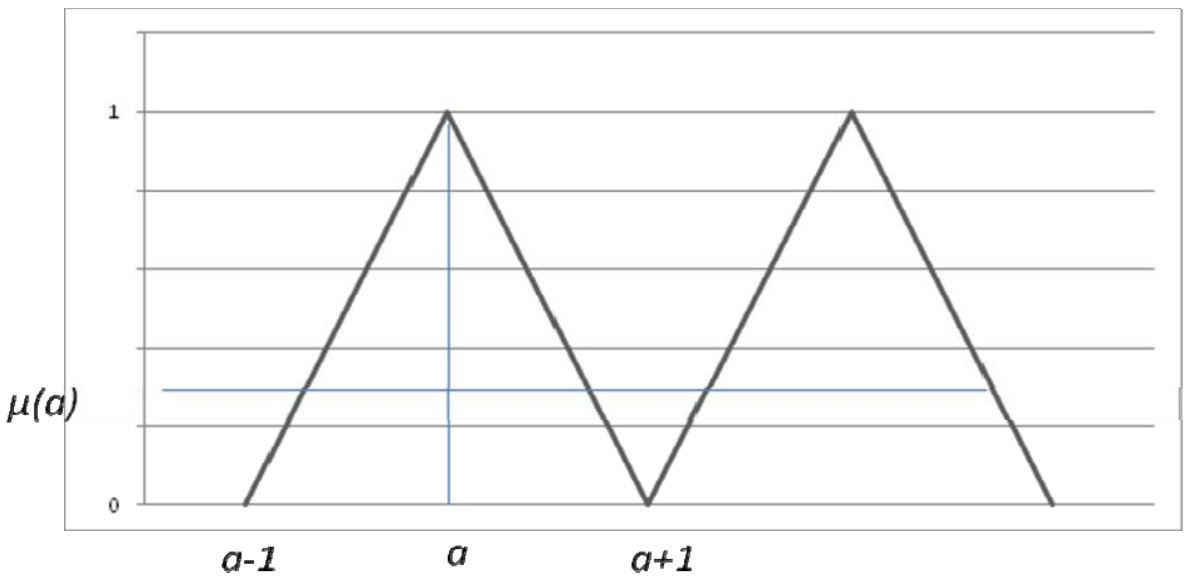

Figure 1 - Construction of the triangular fuzzy number

Bearing in mind that the calculation has been done using the eigenvector method, the rules of calculation with the triangular fuzzy numbers are as follows:

$$
\begin{aligned}
& 1 / a_{i j}=\left\{\frac{1}{a_{i j}+\alpha}, \frac{1}{a_{i j}}, \frac{1}{a_{i j}-\alpha}\right\}, \\
& a_{1}^{\prime} \oplus a_{2}^{\prime}=\left\{a_{11}^{\prime} \oplus a_{21}^{\prime}, a_{12}^{\prime} \oplus a_{22}^{\prime}, a_{13}^{\prime} \oplus a_{23}^{\prime}\right\}, \\
& a_{1}^{\prime} \div a_{2}^{\prime}=\left\{a_{11}^{\prime} \div a_{23}^{\prime}, a_{12}^{\prime} \div a_{22}^{\prime}, a_{13}^{\prime} \div a_{21}^{\prime}\right\},
\end{aligned}
$$

where is:

$$
\begin{aligned}
& a_{1}^{\prime}=\left\{a_{11}^{\prime}, a_{12}^{\prime}, a_{13}^{\prime}\right\} \\
& a_{2}^{\prime}=\left\{a_{21}^{\prime}, a_{22}^{\prime}, a_{23}^{\prime}\right\}
\end{aligned}
$$


Defuzzification into the crisp value has been done as follows:

$$
w=\frac{\left(w_{11}^{\prime}, w_{12}^{\prime}, w_{13}^{\prime}\right)}{3}
$$

The consistency of the results has been tested by the consistency ratio applying the following equation (Pamučar, 2017):

$C R=\frac{C I}{R I}$

CI - Consistency index.

Where is $C I=\frac{\lambda_{\max }-n}{n-1}$

$\lambda_{\max }$ - Maximum eigenvector of the matrix of comparison (equation 7):

$\lambda_{\max }=\frac{1}{n} \sum_{i=1}^{n} \lambda_{i}$

$\lambda_{i}=\frac{b_{i}}{w_{i}}$

Value $b_{i}$ have been calculated by the equation 9 :

$$
\left[\begin{array}{l}
b_{1} \\
b_{2} \\
b_{n}
\end{array}\right]=\left[\begin{array}{l}
a_{11} a_{12} a_{1 n} \\
a_{21} a_{22} a_{2 n} \\
a_{n 1} a_{n 2} a_{n n}
\end{array}\right]\left[\begin{array}{l}
w_{1} \\
w_{2} \\
w_{n}
\end{array}\right]
$$

$R I$ - Random index, which depends on the number of rows - columns of the matrix $\mathrm{n}$ (Pamučar, 2017). If $C R \leq 0.10$ then the result is consistent.

\section{Prioritization of Criteria for Selection of Anti-Aircraft Missile System}

On the basis of the described procedure, the initial preference matrix for the criteria has been established: affordability $(A)$, spatial performance $(B)$, time performance $(C)$, safety (D), and radar support capability of air defence weapons (E). 
The Prioritization of Criteria for the Selection of Radar for the Air Traffic Control and Protection ...

Table 1 - Pairwise comparison matrix

\begin{tabular}{cccccc}
\hline K & A & B & C & D & E \\
\hline A & $(1,1,1)$ & $(2,3,4)$ & $(2,3,4)$ & $(4,5,6)$ & $(3,4,5)$ \\
B & $(0.25,0.33,0.5)$ & $(1,1,1)$ & $(2,3,4)$ & $(4,5,6)$ & $(1,2,3)$ \\
C & $(0.25,0.33,0.5)$ & $(0.25,0.33,0.5)$ & $(1,1,1)$ & $(1,1,1)$ & $(2,3,4)$ \\
D & $(0.17,0.2,0.25)$ & $(0.17,0.2,0.25)$ & $(0.25,0.33,0.5)$ & $(1,1,1)$ & $(4,5,6)$ \\
E & $(0.2,0.25,0.33)$ & $(0.33,0.5,1)$ & $(0.25,0.33,0.5)$ & $(0.17,0.2,0.25)$ & $(1,1,1)$ \\
\hline
\end{tabular}

On the basis of the values from the preference matrix according to equation 4 , a matrix of normalized values has been calculated (Saaty, 1980):

$$
a_{i j}^{\prime \prime}=\frac{a_{i j}^{\prime}}{\sum_{j=1}^{n} a_{i j}^{\prime}}
$$

Where is:

$$
\begin{aligned}
& a_{i j}^{\prime \prime}=\left\{a_{i j 1}^{\prime \prime}, a_{i j 2}^{\prime \prime}, a_{i j 3}^{\prime \prime}\right\}, \\
& a_{i j 1}^{\prime \prime}=\frac{a_{i j 1}^{\prime}}{\sum_{j=1}^{n} a_{i j 3}^{\prime}}, a_{i j 2}^{\prime \prime}=\frac{a_{i j 2}^{\prime}}{\sum_{j=1}^{n} a_{i j 2}^{\prime}}, a_{i j 3}^{\prime \prime}=\frac{a_{i j 3}^{\prime}}{\sum_{j=1}^{n} a_{i j 1}^{\prime}}
\end{aligned}
$$

Table 2 - Normalized pairwise comparison matrix (for criteria)

\begin{tabular}{cccccc}
\hline K & A & B & C & D & E \\
\hline A & $(0.39,0.47,0.53)$ & $(0.29,0.59,1.06)$ & $(0.2,0.39,0.72)$ & $(0.28,0.4,0.58)$ & $(0.15,0.26,0.45)$ \\
B & $(0.09,015,0.26)$ & $(0.14,0.19,0.26)$ & $(0.2,0.39,0.72)$ & $(0.28,0.4,0.58)$ & $(0.05,0.12,0.27)$ \\
C & $(0.09,015,0.26)$ & $(0.03,0.06,0.13)$ & $(0.1,0.13,0.18)$ & $(0.07,0.08,0.09)$ & $(0.1,0.2,0.36)$ \\
D & $(0.06,0.09,0.13)$ & $(0.02,0.03,0.06)$ & $(0.02,0.04,0.09)$ & $(0.07,0.08,0.09)$ & $(0.21,0.33,0.54)$ \\
E & $(0.07,0.11,0.17)$ & $(0.04,0.09,0.26)$ & $(0.02,0.04,0.09)$ & $(0.01,0.01,0.02)$ & $(0.05,0.06,0.09)$ \\
\hline
\end{tabular}


From Table 2, the relative values $W$ have been calculated by the equation 2,4 , and 12 , which are shown in Table 3.

$$
w_{i}=\sum_{j=1}^{n} a_{i j}^{\prime \prime} /
$$

Table 3 - Weight values of criteria

\begin{tabular}{ccccccc}
\hline K & A & B & C & D & E & $w_{i}$ \\
\hline A & $(0.39,0.47,0.53)$ & $(0.29,0.59,1.06)$ & $(0.2,0.39,0.72)$ & $(0.28,0.4,0.58)$ & $(0.15,0.26,0.45)$ & 0.42 \\
B & $(0.09,015,0.26)$ & $(0.14,0.19,0.26)$ & $(0.2,0.39,0.72)$ & $(0.28,0.4,0.58)$ & $(0.05,0.12,0.27)$ & 0.25 \\
C & $(0.09,015,0.26)$ & $(0.03,0.06,0.13)$ & $(0.1,0.13,0.18)$ & $(0.07,0.08,0.09)$ & $(0.1,0.2,0.36)$ & 0.13 \\
D & $(0.06,0.09,0.13)$ & $(0.02,0.03,0.06)$ & $(0.02,0.04,0.09)$ & $(0.07,0.08,0.09)$ & $(0.21,0.33,0.54)$ & 0.12 \\
E & $(0.07,0.11,0.17)$ & $(0.04,0.09,0.26)$ & $(0.02,0.04,0.09)$ & $(0.01,0.01,0.02)$ & $(0.05,0.06,0.09)$ & 0.07 \\
\hline
\end{tabular}

On the basis of equation 7 , it is calculated $\lambda_{\text {max }}=5.45$, and $C I=0.11$. For $n=5 \Rightarrow R I=1.11$ (Saaty, 1980). On the basis of equation 5 , it is calculated $C R=0.09$, and it is lower than 0.1 , so the result is consistent (there is no need for corrections of the comparison). The final ranking of the criteria for the selection of radar for the airspace control and protection is shown in Figure 2.

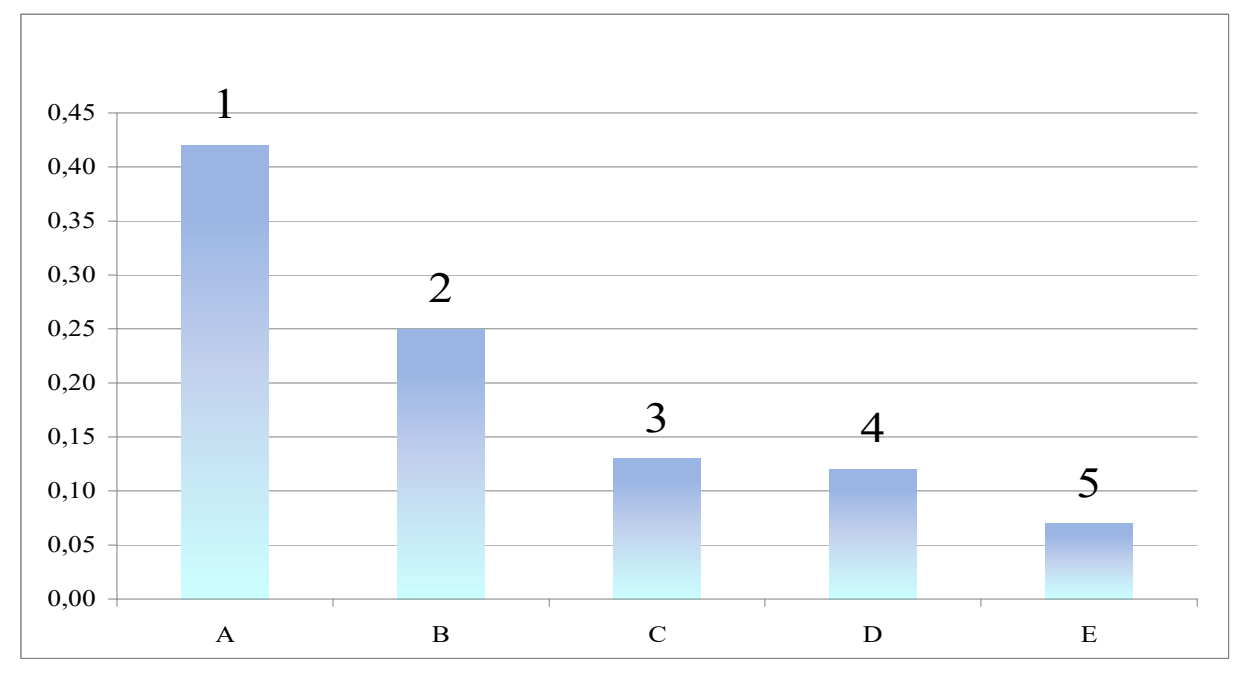

Figure 2 - Weights of radar selection criteria 
The Prioritization of Criteria for the Selection of Radar for the Air Traffic Control and Protection ...

By applying the same procedures, the weights values of attributes have been calculated, which are shown in Table 4, where the proposed model of criteria and attributes with weight values is presented.

Table 4 - Proposed model for selection of radar for the airspace control and protection

\begin{tabular}{ccccccc}
\hline \multicolumn{2}{l}{ The weights values of attributes } & & & $w_{i}$ \\
\hline $\mathrm{A}$ & $\mathrm{A} 1$ & $\mathrm{~A} 2$ & $\mathrm{~A} 3$ & $\mathrm{~A} 4$ & $\mathrm{~A} 5$ & 0.42 \\
$\mathrm{a} w_{i}$ & 0.03 & 0.1 & 0.08 & 0.12 & 0.11 & \\
$\mathrm{~B}$ & $\mathrm{~B} 1$ & $\mathrm{~B} 2$ & $\mathrm{~B} 3$ & $\mathrm{~B} 4$ & & 0.25 \\
$\mathrm{~b} w_{i}$ & 0.12 & 0.02 & 0.05 & 0.06 & & \\
$\mathrm{C}$ & $\mathrm{C} 1$ & $\mathrm{C} 2$ & $\mathrm{C} 3$ & $\mathrm{C} 4$ & & 0.13 \\
$\mathrm{c} w_{i}$ & 0.04 & 0.06 & 0.01 & 0.02 & & \\
$\mathrm{D}$ & $\mathrm{D} 1$ & $\mathrm{D} 2$ & $\mathrm{D} 3$ & $\mathrm{D} 4$ & $\mathrm{D} 5$ & 0.12 \\
$\mathrm{~d} w_{i}$ & 0.02 & 0.02 & 0.01 & 0.04 & 0.03 & \\
$\mathrm{E}$ & $\mathrm{E} 1$ & $\mathrm{E} 2$ & $\mathrm{E} 3$ & $\mathrm{E} 4$ & & 0.07 \\
$\mathrm{e} w_{i}$ & 0.025 & 0.02 & 0.02 & 0.005 & & \\
\hline
\end{tabular}

The consistency ratio for all the criteria and attributes is less than 0.1 .

\section{Discussion}

The prioritization of the criteria and attributes of the criteria for the selection of radar for the airspace control and protection has not been the topic of any scientific paper so far. Most of the papers are related to the improvement of certain radar characteristics, the creation of new technological solutions and the modernization of the existing radar systems. However, there are some studies that have researched the evaluation of criteria and the selection of optimum weapons and equipment systems. For example, in his research, Župac (2013), by applying the AHP method, evaluated the criteria and attributes of anti-aircraft missile system. Petrović \& Kankaraš (2017) researched the weights of criteria for the selection of anti-aircraft missile system by the DEMATEL method. In this research, prioritization was carried out by four criteria (economy, effectiveness, maintenance, and combat abilities of the anti-aircraft system).

However, despite these studies, in this paper, for the first time, prioritization has been carried out by the fuzzy-AHP method, which is one of the tools for multi-criteria decision making, where the number of respondents is small (less than 10, in this case only four experts), and where uncertainty, during gathering data, has very important influence, which was not the case in previous papers. In this paper, the selection of experts from specialists has been carried out, which reduced the inconsistency in the decision-making 
process (the influence of stronger factors on the weaker). It is also necessary to emphasize that the paper relates to the need for prioritization of the criteria for the selection of radar for use during peacetime. The criteria for radar selection are as follows: affordability with the weight of 0.42 , then spatial performance with the weight of 0.25 , then time performance with 0.13 , safety with 0.12 and and the radar support capability of air defence weapons with the weight of 0.07 .

On the basis of the results of the research, it can be concluded that the experts think that the economic aspect, especially procurement conditions, have a great influence on the selection and financial sustainability of equipping and exploiting radar (bearing in mind the relatively small domestic gross product of the country). It is also interesting that spatial performance has more importance than time performance, while the importance of safety, as well as the radar support capability of air defence weapons is relatively small (because the procurement of radars is aimed at performing tasks in peace). It is obvious that the experts believe that the tendency of the radar acquisition should be focused on increasing spatial performance, which would reduce the number of radar units. Moreover, according to the expert opinion, it is necessary to significantly increase the ability of time performance, or rapid reaction of the entire air defence system in the case of aviation violation (Petrović et al., 2015).

On the basis of the aforementioned research results, it can be concluded that the aim of the research is fulfilled and that the general hypothesis is positively verified. The proposed model can be upgraded by applying highly qualified multi-criteria decision making methods, taking into consideration the degree of confidence of the experts (TOPSIS, VIKOR, MAICRA, etc).

\section{Conclusion}

The selection of optimum radar is one of the most important tasks of air force and air defense in the future. This is the consequence of the influence that operations, which are carried out by air force and air defence units have on modern armed conflicts, as well as the significance of the air defence system in performing the airspace control and protection in peace. The task of the airspace control and protection is an irreplaceable segment of air traffic management, whose conduct is impossible without modern radar resources.

The future research can also focus on improving the model for the selection of not only radar, but also other weapons and equipment systems, taking into consideration technological-economic analysis. The selection of weapons and equipment systems for the air force and air defence is a complex process, which in the long-term directs the development of the organizational and functional structure of air force and air defence units. Therefore, it is necessary to provide an interdisciplinary approach with respect to both professional and academic public.

\section{Literature}

[1] Božanić, D., Pamučar, D. \& Bojanić, D. (2015). Modification of the analytic hierarchy process (ahp) method using fuzzy logic: fuzzy ahp approach as a support to the decision making process concerning engagement of the group for additional hindering. Serbian Journal of Management, $10(2), 151-171$. 
The Prioritization of Criteria for the Selection of Radar for the Air Traffic Control and Protection ...

[2] Chen, J., Chen, L., \& Sun D. (2017). Air traffic flow management under uncertainty using chance - constrained optimization. Transportation Research, Part B 102, 124-141. doi.org/10.1016/j.trb.2017.05.014

[3] Dagdeviren, M., Yavuz, S. \& Kilinc, N. (2009). Weapon selection using the AHP and TOPSIS methods under fuzzy environment. Expert Systems with Applications, Vol. 2009, No. 36, 8143-8151. preuzeto sa: www.elsevier.com/locate/eswa

[4] Mavris, D. \& DeLaurentis, D. (1995). An Integrated Approach to Military Aircraft Selection and Concept Evaluation. The 1st AIAA Aircraft Engineering, Technology, and Operations Congress, Los Angeles (1-11). American Institute of Aeronautics and Astronautics

[5] Menon, P. K., Sweriduk, G. D., \& Bilimoria, D. (2004). New Approach for Modeling, Analysis, and Control of Air Traffic Flow. Journal of Guidance, Control, and Dynamics, September, 27 (5), 737-744. doi: org/10.2514/1.2556

[6] Pamucar, D., Petrovic, I. \& Cirovic, G. (2018). Modification of the Best-Worst and MABAC methods: A novel approach based on interval-valued fuzzy-rough numbers, Expert Systems with Applications, 91, 89-106.

[7] Petrović, I. \& Kankaraš. M. (2017). Determination and Evaluation Criteria for Equipping the Small Country with Anti-aircraft Missile System. ICMNEE 2017. Beograd.

[8] Petrović, I., Kankaraš, M. \& Cvetković, K. (2015). Significance and Prospects of the Development of Defence System. Vojno delo, Vol. 67, No. 6, 86-98. doi: 10.5937/vojdelo1506086P

[9] Petrović, I., Kankaraš, M., \& Gordić, P. (2014). Model proračuna dugoročne finansijske održivosti izvođenja operacije kontrole i zaštite vazdušnog prostora (Long-term Financial Sustainability of Airspace Control and Protection Operation - Calculation Model). Vojno delo, 66 (6), 219-226. doi: 10.5937/vojdelo1404219P

[10] Saaty, T. L. (1980). The analytic hierarchy process. New York. McGraw-Hill.

[11] Vahdani, B., Tavakkoli-Moghaddam, R., Meysam Mousavi, S., \& Ghodratnama. A. (2013). Soft computing based on new interval-valued fuzzy modified multi-criteria decision-making method, Applied Soft Computing, 13, 165-172

[12] Vlačić, S. (2012). Definisanje kriterijuma za izbor višenamenskog borbenog aviona za potrebe Vazduhoplovstva i protivvazduhoplovne odbrane Vojske Srbije [in Serbian] (Defining the criteria for selecting a multirole combat aircraft for the purposes of the Air Force and Air Defense Defense of the Serbian Armed Forces). Beograd: Univerzitet odbrane.

[13] Gordić, M. \& Petrović, I. (2014). Raketni sistemi u odbrani malih država [in Serbian] (Antiaircraft missile systems in defence of small countries). Beograd: MC Odbrana.

[14] Sretović, S. (2018). Određivanje i vrednovanje kriterijuma za izbor radarsko-računarskih sredstava za potrebe kontrole i zaštite vazdušnog prostora [in Serbian] (Determination and evaluation of criteria for selection of radar for the purpose of airspace control and protection). Univerzitet odbrane. Beograd.

[15] Župac, G. (2013). Model određivanja i evaluacije kriterijuma za izbor raketnog sistema protivvazduhoplovne odbrane srednjeg dometa [in Serbian] (A model for determination and evaluation of the criteria for selection of a middle-range anti-aircraft missile system). Beograd. Univerzitet odbrane 